\title{
An 11-month-old girl with central precocious puberty caused by hypothalamic hamartoma
}

\author{
Da Young Yoon, MD, \\ Jae Hyun Kim, MD
}

Department of Pediatrics, Inje University Ilsan Paik Hospital, Inje University College of Medicine, Goyang, Korea
Received: 30 August, 2016 Revised: 23 October, 2016 Accepted: 7 December, 2016

Address for correspondence: Jae Hyun Kim, MD

Department of Pediatrics, Inje University IIsan Paik Hospital, Inje University College of Medicine, 170 Juhwa-ro, Ilsanseo-gu, Goyang 10380, Korea

Tel: +82-31-910-7942

Fax: +82-31-910-7108

E-mail: pedendo@paik.ac.kr

http://orcid.org/0000-0002-02037443
Central precocious puberty (CPP) is caused by premature activation of the hypothalamic-gonadal axis, and must be treated adequately. In particular, CPP that occurs at a relatively young age or in boys is likely to be caused by an organic lesion. Hypothalamic hamartoma $(\mathrm{HH})$ is the most common organic cause of CPP. The present case report describes an 11-month-old female infant who presented with vaginal bleeding and rapidly progressive secondary sex characteristics from the age of 6 months. She was diagnosed with CPP following the detection of $\mathrm{HH}$ via magnetic resonance imaging. The infant girl was successfully treated with gonadotropinreleasing hormone agonist. After 6 months, her breast had regressed and clinical and radiological follow-up demonstrated stable findings with no evidence of tumor growth or secondary sexual characteristics until the fourth year after the initiation of treatment. This patient is the one of the youngest infants presenting with CPP and $\mathrm{HH}$ in Korea; treatment was successful over a relatively long follow-up period.

Keywords: Hypothalamic hamartoma, Precocious puberty, Menstruation

\section{Introduction}

Precocious puberty (PP) is defined as the onset of the clinical signs of puberty at an earlier age, including breast budding before the age of 8 years in girls and testicular enlargement before 9 years in boys. Central precocious puberty $(\mathrm{CPP})$ results from premature activation of the hypothalamic-pituitary-gonadal axis.

Of the cases of idiopathic CPP, $>90 \%$ occur in girls and $<10 \%$ in boys ${ }^{1)}$. Common organic causes of CPP are hypothalamic hamartoma $(\mathrm{HH})$, hydrocephalus, tumors, infections, congenital defects, ischemia, radiation, and brain injury.

$\mathrm{HH}$, the most common cause of CPP, involves congenital malformation of the central nervous system. Patients with CPP exhibit symptoms such as epileptic syndrome (including gelastic seizure), PP, progressive cognitive decline, and behavioral disorders. In particular, 75\% of PP cases that occur at a younger age (1-3 years) are due to $\mathrm{HH}$; therefore, younger patients with $\mathrm{PP}$ require evaluations of the central causes of $\mathrm{PP}^{2)}$.

In this case report, we describe an 11-month-old female infant with CPP caused by $\mathrm{HH}$ who presented with vaginal bleeding and rapidly progressive secondary sexual characteristics. She was treated with gonadotropin-releasing hormone $(\mathrm{GnRH})$ agonist, which resulted in successful suppression of pubertal progression.

\section{Case report}

An 8-month-old infant girl presented with bloody vaginal discharge. She was born vaginally after $37^{+4}$ weeks of gestation with a birth weight of $2.94 \mathrm{~kg}$ and was the first child of healthy parents. Her mother's and father's height measurements are 160 and $168 \mathrm{~cm}$, respectively. Her mother's menarcheal age was 13 years and her father experienced normal pubertal 
development. She was healthy until 2 months before admission. At around 6 months of age, bloody discharge was noted in her diaper, and 1 week previously, mucoid bloody discharge was present for 5 days. Her parents visited a local clinic and pelvic ultrasonography was performed, which showed an endometrial thickness of $17 \mathrm{~mm}$ and a cyst in the uterine appendage. She was referred to our hospital for further evaluation.

At the time of her first visit, her height was $67.0 \mathrm{~cm}(-1.42$ standard deviation score [SDS]), weight $7.9 \mathrm{~kg}(-0.66 \mathrm{SDS})$, bone age $2-2^{+6}$ years, breast Tanner stage II, and pubic hair Tanner stage II. On her physical examination, no other abnormalities were observed. Laboratory tests demonstrated an elevated serum estradiol level of $37.4 \mathrm{pg} / \mathrm{mL}$; basal luteinizing hormone (LH) and follicle stimulating hormone (FSH) levels were 4.0 and $4.4 \mathrm{IU} / \mathrm{L}$, respectively. No considerable findings were detected during pelvic ultrasonography. The patient was scheduled for a follow-up after 3 months to examine pubertal progression.

At 11 months of age, the patient experienced 2 episodes of bloody vaginal discharge during the previous 3 months and her breasts progressed to Tanner stage III. At that time, her height was $77.0 \mathrm{~cm}(0.75$ SDS $)$ and she weighed $9.1 \mathrm{~kg}(-0.24$ SDS $)$. Her basal serum LH, FSH, and estradiol levels were $1.3 \mathrm{IU} / \mathrm{L}, 0.9 \mathrm{IU} /$ $\mathrm{L}$ and $80.8 \mathrm{pg} / \mathrm{mL}$, respectively. Thyroid function tests showed no specific abnormalities. On the GnRH stimulation test, peak LH and FSH levels were 65.9 and $12.1 \mathrm{IU} / \mathrm{L}$, respectively, which was compatible with a diagnosis of CPP. The other results from the initial hormonal evaluation were within the normal limits for her chronological age. Brain magnetic resonance imaging (MRI) was performed to elucidate the organic cause, which demonstrated a well-defined isodense 1 -cm-sized nonenhanced mass in the tuber cinereum on T1- weighted imaging, and this finding corresponded with HH (Fig. 1). Abdominopelvic computed tomography showed an enlarged ovary size for her chronological age (Fig. 2). As a result, the patient was diagnosed with CPP caused by HH. Her electroencephalogram demonstrated no epileptiform discharge.

Following diagnosis, a GnRH agonist (Leuplin depot, Takeda Pharmaceutical Co. Ltd., Osaka, Japan) was administered
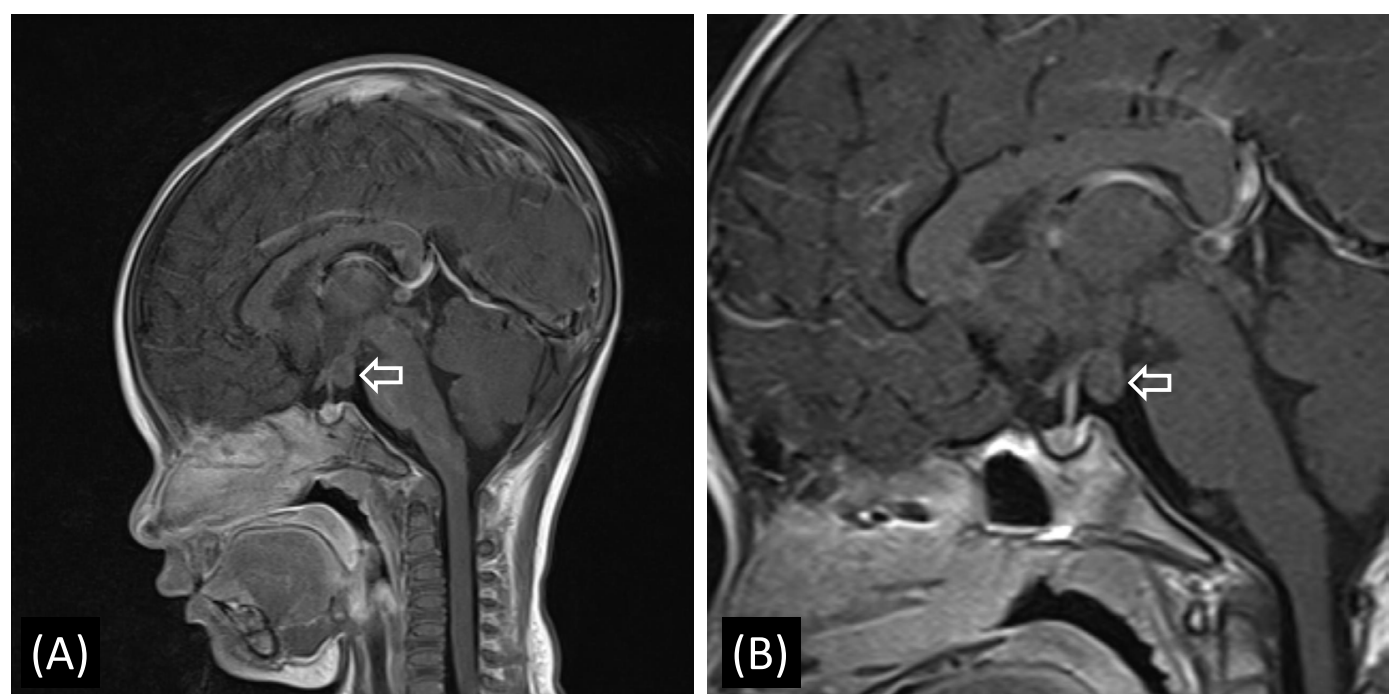

Fig. 1. Magnetic resonance imaging findings of the patient. (A) T1-weighted sagittal image obtained at diagnosis showing a hypothalamic hamartoma (diameter: $1.0 \mathrm{~cm}$ ) at the tuber cinereum with no enhancement (arrow). (B) T1-weighted sagittal image obtained at the age of $4^{+11}$ years showing no interval changes (arrow).

Table 1. Clinical course of the patients

\begin{tabular}{|c|c|c|c|c|c|c|c|c|}
\hline \multirow{2}{*}{$\begin{array}{l}\text { Chronological age } \\
\left(y r^{+m o}\right)\end{array}$} & \multirow{2}{*}{$\begin{array}{c}\text { Bone age } \\
\left(\mathrm{yr}^{+\mathrm{mo}}\right)\end{array}$} & \multirow{2}{*}{$\begin{array}{l}\text { Height } \\
(\mathrm{SDS})(\mathrm{cm})\end{array}$} & \multirow{2}{*}{$\begin{array}{l}\text { Weight } \\
\text { (SDS) (kg) }\end{array}$} & \multirow{2}{*}{$\begin{array}{l}\text { Body mass index } \\
\left(\text { SDS) }\left(\mathrm{kg} / \mathrm{m}^{2}\right)\right.\end{array}$} & \multicolumn{2}{|c|}{$\begin{array}{l}\text { Sexual maturity rate } \\
\text { (Tanner stage) }\end{array}$} & \multirow{2}{*}{$\begin{array}{l}\text { Height velocity } \\
(\mathrm{cm} / \mathrm{yr})\end{array}$} & \multirow{2}{*}{$\begin{array}{c}\text { GnRH agonist dose } \\
(\mu \mathrm{g} / \mathrm{kg})\end{array}$} \\
\hline & & & & & Breast & Pubic hair & & \\
\hline$\overline{0^{+11}}$ & 3 & $77.0(0.75)$ & $9.1(-0.24)$ & 15.35 & III & $\|$ & - & 82 \\
\hline $1^{+5}$ & $3-3^{+6}$ & $82.5(0.51)$ & $11.2(0.38)$ & 16.46 & I & I & 11 & 66 \\
\hline $1^{+10}$ & $3^{+6}$ & $85.0(0.01)$ & $11.5(-0.15)$ & 15.92 & I & I & 5.4 & 65 \\
\hline $2^{+5}$ & $3^{+6}$ & $90.5(0.18)$ & $13.2(0.20)$ & $16.12(-0.05)$ & I & । & 9.9 & 56 \\
\hline $2^{+10}$ & $3^{+6}-4^{+2}$ & $93.0(0.04)$ & $13.5(-0.09)$ & $15.61(-0.26)$ & I & I & 5.8 & 55 \\
\hline $3^{+5}$ & $4^{+2}$ & $96.9(-0.05)$ & $15.5(0.45)$ & $16.51(0.62)$ & I & I & 7 & 48 \\
\hline $3^{+11}$ & $4^{+2}-5$ & $100.5(-0.05)$ & $16.0(0.16)$ & $15.84(0.24)$ & I & । & 6.7 & 46 \\
\hline $4^{+5}$ & 5 & $103.7(-0.11)$ & $17.4(0.33)$ & $16.18(0.54)$ & I & । & 6.8 & 43 \\
\hline $4^{+11}$ & $5-6$ & $106.9(-0.14)$ & $18.8(0.45)$ & $16.45(0.71)$ & I & । & 6.1 & 39 \\
\hline
\end{tabular}

SDS, standard deviation score; GnRH, gonadotropin releasing hormone. 
Table 2. Gonadotropin-releasing hormone (GnRH) stimulation test during follow-up

\begin{tabular}{|c|c|c|c|c|c|c|}
\hline \multirow{2}{*}{ Chronological age $\left(\mathrm{yr}^{+\mathrm{mo}}\right)$} & \multirow{2}{*}{ Bone age $\left(\mathrm{yr}^{+\mathrm{mo}}\right)$} & \multicolumn{5}{|c|}{ GnRH stimulation test } \\
\hline & & Basal LH (IU/L) & Basal FSH (IU/L) & Peak LH (IU/L) & Peak FSH (IU/L) & Estradiol $(\mathrm{pg} / \mathrm{mL})$ \\
\hline $0^{+11}$ & 3 & 1.3 & 0.9 & 65.9 & 12.1 & 80.8 \\
\hline $1^{+5}$ & $3-3^{+6}$ & 0.6 & 1.9 & 5.0 & 5.0 & $<5.0$ \\
\hline $1^{+10}$ & $3^{+6}$ & 0.3 & 0.7 & 3.8 & 2.3 & $<5.0$ \\
\hline $2^{+5}$ & $3^{+6}$ & 0.4 & 0.6 & 2.2 & 1.6 & $<5.0$ \\
\hline $2^{+10}$ & $3^{+6}-4^{+2}$ & 0.5 & 0.6 & 1.8 & 1.1 & $<5.0$ \\
\hline $3^{+5}$ & $4^{+2}$ & 0.5 & 1.7 & 1.7 & 2.7 & $<5.0$ \\
\hline $3^{+11}$ & $4^{+2}-5$ & 0.3 & 0.8 & 1.4 & 1.9 & $<5.0$ \\
\hline $4^{+5}$ & 5 & 0.1 & 1.5 & 1.4 & 3.4 & $<5.0$ \\
\hline $4^{+11}$ & $5-6$ & 0.1 & 0.7 & 1.0 & 1.6 & $<5.0$ \\
\hline
\end{tabular}

$\mathrm{LH}$, luteinizing hormone, $\mathrm{FSH}$, follicular stimulating hormone.
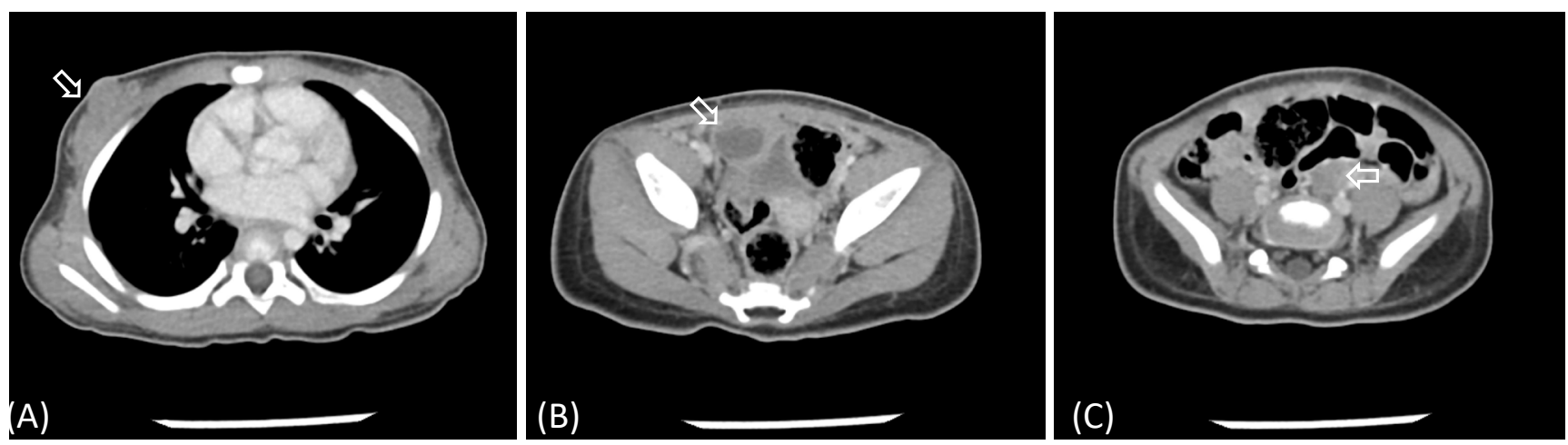

Fig. 2. Abdominopelvic computed tomography findings of the patient obtained at diagnosis. (A) Breast parenchyma was predominantly observed (arrow). (B, C) Both ovaries were observed to be predominantly large for her age (B: $1.9 \mathrm{~cm} \times 1.6 \mathrm{~cm}$ [arrow]; C: $1.7 \mathrm{~cm} \times 1.0 \mathrm{~cm}$ [arrow]).

subcutaneously every 4 weeks. After 6 months, her breasts had regressed to Tanner stage I and her serum plasma estradiol level was $<5 \mathrm{pg} / \mathrm{mL}$. Subsequent tests for GnRH stimulation, peak LH, FSH and estradiol levels demonstrated that the levels had fallen to $5.0 \mathrm{IU} / \mathrm{L}, 5.0 \mathrm{IU} / \mathrm{L}$, and $<5.0 \mathrm{pg} / \mathrm{mL}$, respectively. Following 1 year of GnRH agonist treatment, the patient's breasts remained at Tanner stage I and peak LH, FSH, and estradiol levels further decreased to $3.8 \mathrm{IU} / \mathrm{L}, 2.3 \mathrm{IU} / \mathrm{L}$, and $<5.0$ $\mathrm{pg} / \mathrm{mL}$, respectively (Tables 1,2 ).

The duration of follow-up was 4 years. Following the initiation of GnRH agonist therapy, no further secondary sexual characteristics or vaginal bleeding were observed. Serum peak LH levels after GnRH stimulation testing were well suppressed. Height velocity was maintained at $6-7 \mathrm{~cm}$ per year and her bone age is consistent with her chronological age to date (Tables 1,2). Adverse events of GnRH agonist treatment were not noted. Symptoms and signs associated with $\mathrm{HH}$, such as seizures, psychological problems, and cognitive decline were not observed. Follow-up brain MRI imaging at age 1 and 4, demonstrated that the $\mathrm{HH}$ did not exhibit any changes in size or contouring during GnRH agonist treatment (Fig. 1).

\section{Discussion}

HHs are predominantly located at the base of the hypothala- mus where they develop as an outgrowth of the floor of the third ventricle. HH are rare congenital non-neoplastic lesions containing mature tissue $e^{3)}$. The incidence of $\mathrm{HH}$ is not well documented; however, it is the most common organic cause of CPP in both boys and girls. Several studies have reported the incidence of HHs in patients with isosexual PP, with values ranging from $14 \%$ to $58 \%{ }^{4)}$.

HH has a triad of symptoms, including gelastic seizure, PP, and behavior and cognitive disorders. The existence of symptoms or their severity is variable between patients. Patients with PP typically present with an onset of pubertal development at a very young age usually $<4$ years of age ${ }^{5}$. Therefore, relatively early presentation of PP or boys with PP requires clinical evaluation for brain tumors, such as $\mathrm{HH}$.

Han et al. ${ }^{6)}$ analyzed the clinical characteristics and outcome of 11 patients with $\mathrm{HH}$ in a single center in Korea for 11 years from 1986. The mean age at symptom presentation was 5 years and 8 month (range, 1.1-14.1 years), with symptoms including gelastic seizure $(\mathrm{n}=7,64 \%), \mathrm{PP}(\mathrm{n}=6,55 \%)$ and behavioral or psychological disorders $(n=9,82 \%)$. Seizure symptoms were not responsive to medical treatment and were successfully controlled by surgery. Lee et al. ${ }^{7}$ also analyzed $11 \mathrm{HH}$ patients in Koreas single medical center for 13 years, and PP was detected in 7 patients (64\%) and seizure in 7 patients (64\%). Among the 7 patients with PP, PP was demonstrated to be the first symptom 
of HH. The mean age of symptom onset was 5.4 years. Debeneix et al. ${ }^{8)}$ analyzed 19 patients with $\mathrm{HH}$ for 17 years in France. The mean age at diagnosis was $5.7 \pm 4.1$ (standard deviation) years. CPP was detected in 14 patients $(73.6 \%)$, seizure in 9 patients (47.4\%), isolated CPP in 9 patients, and CPP and seizure in 4 patients, respectively. Notably, 16 of 19 patients exhibited no changes in the contour and size of the $\mathrm{HH}$ after a mean followup period of $4.2 \pm 3.3(0.5-10.2)$ years

The optimal tool for diagnosis of $\mathrm{HH}$ is high-resolution brain MRI. Symptoms of HH are closely correlated with the position of $\mathrm{HH}$ and its connections to surrounding tissue, such as the hypothalamus. Seizures commonly occur in patients with $\mathrm{HH}$ that infiltrate the hypothalamus as opposed to in patients with pedunculated $\mathrm{HH}^{91}$. However, $>45 \%$ of $\mathrm{HH}$ are mixed types that exists in the third ventricle and extends inferiorly into the interpeduncular fossa, and in this case, both seizures and PP were observed in the patients ${ }^{10}$. Patients with pedunculated $\mathrm{HH}$ s without infiltrating hypothalamus, which are those located below the third ventricle, rarely present with seizures. Rather, these lesions are commonly associated with $\mathrm{CPP}^{11}$. The present patient was thought to possess a pedunculated $\mathrm{HH}$ as she exhibited isolated PP. However, regular follow-up is warranted for this patient, since seizure or behavior associated with a cognitive disorder might occur.

The apparent association between HH and CPP is still not completely understood. Judge et al. ${ }^{12)}$ reported that luteinizing hormone-releasing hormone (LHRH) immunoreactivity was detected in surgically removed $\mathrm{HH}$, indicating that the $\mathrm{HH}$ has a heterotopic LHRH pulse generator and follow puberty. Boyko et al. ${ }^{13)}$ and Striano et al. ${ }^{14)}$ reported that a pedunculated $\mathrm{HH}$ compresses the pituitary stalk, interrupting the inhibitory pathways from the hypothalamus between the pituitary posterior lobe. Consequently, excessive secretion of GnRH is transferred to the hypothalamus through the tuber cinereum, which provokes abnormal endocrine function.

In infancy, elevation of LH and FSH levels is referred to as mini puberty; symptoms such as vaginal bleeding or breast budding might be observed transiently ${ }^{15}$. Previously reported cases of infants with vaginal bleeding were born preterm or were small for their gestational age. These extreme cases of mini puberty detailed only $1-2$ episodes of vaginal bleeding ${ }^{16,17)}$. In girls, postnatal gonadotropin levels started to decrease after the peak at $1-3$ months of age. However, the present patient was born full-term and was of the appropriate size for gestational age; she experienced vaginal bleeding for 5 days and more than 3 times. Moreover, our patient showed rapid progression of her secondary sexual characteristics during the follow-up period and brain MRI revealed HH. Therefore, we concluded that her pubertal progression was not caused by mini puberty but by $\mathrm{HH}$.

Although the optimum treatment of $\mathrm{HH}$ is surgical removal, complete removal remains difficult owing to the adhesion or invasion of surrounding tissues. Patients with uncontrolled seizures sometimes require surgery. $\mathrm{CPP}$ due to $\mathrm{HH}$ is well controlled by hormonal therapy. GnRH agonist treatment induces persistent sensitization of the GnRH receptor, followed by decreased sensitivity and the expression of the receptor as a result of delayed puberty ${ }^{18}$. Lee et al. ${ }^{7}$ reported that $6 \mathrm{PP}$ patients with $\mathrm{HH}$ were diagnosed before 7 years of age and treated at the appropriate time. Only one patient demonstrated pubertal sign at 10 years 6 months; however, treatment with the $\mathrm{GnRH}$ agonist was initiated due to prominent LH concentration on GnRH stimulation test and the concern about attenuated adult height and emotional distress. Kotwal et al. ${ }^{19)}$ reported the case of a 16-month-old girl who had shown vaginal bleeding from when she was 6 months old, which evolved into a monthly regular cycle and progressive secondary sexual characteristics. The researchers detected HH in her brain MRI. She was treated by GnRH analogue and has shown a good response on two-year follow-up. Acharya et al. ${ }^{20)}$ reported a 4-month-old male infant with CPP due to HH diagnosed in utero. He had a history of accelerated growth since birth and developed secondary sexual characteristics from 3 months of age. To exclude mini puberty, the patient was followed-up after 4 months; his bone age was 18 months and GnRH stimulation test exhibited PP. He was also treated with leuprolide acetate and his growth stabilized after 9 months of follow-up.

We report the clinical course and MRI findings during the 4-year follow-up period of the one of the youngest patients in Korea that exhibited PP as a first symptom of HH. This infant girl with CPP caused by $\mathrm{HH}$ exhibited a good response to the treatment with GnRH agonist. In conclusion, rapidly progressive CPP in infancy requires appropriate laboratory and radiologic evaluation to determine the organic cause, and should be distinguished from extreme mini puberty.

\section{Conflict of interest}

No potential conflict of interest relevant to this article was reported.

\section{References}

1. Pescovitz OH, Comite F, Hench K, Barnes K, McNemar A, Foster C, et al. The NIH experience with precocious puberty: diagnostic subgroups and response to short-term luteinizing hormone releasing hormone analogue therapy. J Pediatr 1986;108:47-54.

2. Shenoy SN, Raja A. Hypothalamic hamartoma with precocious puberty. Pediatr Neurosurg 2004;40:249-52.

3. Jung H, Parent AS, Ojeda SR. Hypothalamic hamartoma: a paradigm/model for studying the onset of puberty. Endocr Dev 2005;8:81-93.

4. Ng SM, Kumar Y, Cody D, Smith CS, Didi M. Cranial MRI scans are indicated in all girls with central precocious puberty. Arch Dis Child 2003;88:414-8.

5. Rousso IH, Kourti M, Papandreou D, Tragiannidis A, Athanasiadou F. Central precocious puberty due to hypothalamic hamartoma in a 7-month-old infant girl. Eur 
J Pediatr 2008;167:583-5.

6. Han SK, Chae JH, Kim KJ, Hwang YS, Han TI, Kim IO. Hypothalamic hamartoma: clinical and MRI features and outcome. J Korean Child Neurol Soc 1997;5:69-75.

7. Lee J, Yu HJ, Kim JY, Kim JH, Lee JI, Shin HJ, et al. Clinical manifestations and treatment of hypothalamic Hamartoma. J Korean Epilepsy Soc 2013;17:8-16.

8. Debeneix C, Bourgeois M, Trivin C, Sainte-Rose C, Brauner R. Hypothalamic hamartoma: comparison of clinical presentation and magnetic resonance images. Horm Res 2001;56:12-8.

9. Freeman JL, Coleman LT, Wellard RM, Kean MJ, Rosenfeld JV, Jackson GD, et al. MR imaging and spectroscopic study of epileptogenic hypothalamic hamartomas: analysis of 72 cases. AJNR Am J Neuroradiol 2004;25:450-62.

10. Kameyama S, Murakami H, Masuda H, Sugiyama I. Minimally invasive magnetic resonance imaging-guided stereotactic radiofrequency thermocoagulation for epileptogenic hypothalamic hamartomas. Neurosurgery 2009;65:438-49.

11. Mittal S, Mittal M, Montes JL, Farmer JP, Andermann F. Hypothalamic hamartomas. Part 1. Clinical, neuroimaging, and neurophysiological characteristics. Neurosurg Focus 2013;34:E6.

12. Judge DM, Kulin HE, Page R, Santen R, Trapukdi S. Hypothalamic hamartoma: a source of luteinizing-hormonereleasing factor in precocious puberty. N Engl J Med 1977;296:7-10.
13. Boyko OB, Curnes JT, Oakes WI, Burger PC. Hamartomas of the tuber cinereum: CT, MR, and pathologic findings. AJNR Am J Neuroradiol 1991;12:309-14.

14. Striano S, Striano P, Sarappa C, Boccella P. The clinical spectrum and natural history of gelastic epilepsy-hypothalamic hamartoma syndrome. Seizure 2005;14:232-9.

15. Kuiri-Hänninen T, Sankilampi U, Dunkel L. Activation of the hypothalamic-pituitary-gonadal axis in infancy: minipuberty. Horm Res Paediatr 2014;82:73-80.

16. de Lange AH, Bocca G. Vaginal bleeding in a 4-monthold preterm girl: extreme minipuberty mimicking central precocious puberty. J Pediatr Endocrinol Metab 2013;26:595-7.

17. Vogiatzi MG, Pitt M, Oberfield S, Alter CA. Menstrual bleeding as a manifestation of mini-puberty of infancy in severe prematurity. J Pediatr 2016;178:292-5.

18. Carel JC, Eugster EA, Rogol A, Ghizzoni L, Palmert MR; ESPE-LWPES GnRH Analogs Consensus Conference Group, et al. Consensus statement on the use of gonadotropin-releasing hormone analogs in children. Pediatrics 2009;123:e752-62.

19. Kotwal N, Yanamandra U, Menon AS, Nair V. Central precocious puberty due to hypothalamic hamartoma in a six-month-old infant girl. Indian J Endocrinol Metab 2012;16:627-30

20. Acharya SV, Gopal RA, Menon PS, Bandgar TR, Shah NS. A rare case of central precocious puberty due to hypothalamic hamartoma diagnosed in utero. Endocr Pract 2010;16:23740. 